\title{
Interdisciplinaridade e Trabalho em Grupo em Nefrologia
}

\author{
Rosemeire Aparecida do Nascimento", Sandra Almazi Primazzi \& Regina C. R. M. Abdulkader \\ Hospital das Clínicas, Universidade de São Paulo, São Paulo, Brasil
}

\begin{abstract}
RESUMO
A constatação da alta prevalência, em pacientes com doenças renais, de sintomas psicopatológicos, da perda da sua qualidade de vida, além das perdas reais, e da falta de informação sobre sua doença e tratamento, aponta para a necessidade da atuação dos profissionais da saúde sobre esses pontos. Através da análise crítica da interdisciplinaridade, em contraponto à multidisciplinaridade, e do alcance que o trabalho grupal apresenta, é feita uma proposta de intervenção junto aos pacientes internados em uma enfermaria de Nefrologia. A intervenção proposta é um grupo interdisciplinar rotativo aberto que trabalhe as diferentes demandas trazidas por esses pacientes. Como exemplo, é apresentado o recorte de um dos grupos realizados onde os diferentes aspectos dessa intervenção são identificados e comentados.
\end{abstract}

Palavras-chave: interdisciplinaridade; trabalho em grupo; Nefrologia.

\begin{abstract}
Interdisciplinarity and Group Work in Nephrology

The high prevalence of psychopathological symptoms among renal patients, the reduced quality of life that adds to their ensuing actual losses, and the lack of information on their illness and treatment, indicates that health professionals should act on these specific points. By means of a critical analysis of interdisciplinarity vis-à-vis multidisciplinarity and taking advantage of the reach of group work, we propose an intervention, consisting of an opened rotating interdisciplinary group, offered to patients admitted to a Nephrology ward, in order to deal with their different demands. As an example, excerpts from one group session are presented, and the various aspects of the intervention are identified and commented on.
\end{abstract}

Keywords: interdisciplinarity; group work; Nephrology.

O tratamento de doenças crônicas traz para as equipes de saúde problemas referentes à não adesão ao tratamento, à dificuldade de muitos pacientes em readaptar-se à vida cotidiana e à percepção de sofrimento psíquico. Esses problemas são intensamente sentidos no acompanhamento de pacientes portadores de doença renal crônica (DRC), cujo número vem crescendo.

A DRC em geral apresenta uma evolução lenta que termina em morte, passando pelo tratamento dialítico e/ou transplante renal ou ambos. O paciente com DRC não apresenta dor ou alterações físicas aparentes, podendo a DRC ser denominada como uma doença "si- lenciosa". Ao receber a indicação para iniciar um tratamento dialítico, o paciente fica "surpreso" pois terá que enfrentar um tratamento invasivo para algo que ainda não foi significado por ele como doença. $\mathrm{O}$ paciente com DRC pode passar anos em tratamento ambulatorial até a perda definitiva da função renal. Esse tempo prolongado pode levar a uma "perda" do diagnóstico, entre o início do acompanhamento e o momento da passagem do acompanhamento ambulatorial para a terapia substitutiva renal (diálise ou transplante).

$\mathrm{O}$ adoecimento e aquilo que o compõe, como o diagnóstico, o tratamento e o prognóstico, exige um

* Endereço para correspondência: Rosemeire Aparecida do Nascimento - rose.nasc@uol.com.br 
processo de elaboração que é particular de cada paciente. Ao adquirir uma doença qualquer, inicialmente revelada a partir de sensações ruins ou estranhas no corpo, dores e mal estar, o paciente passa a atribuir sentidos e construir explicações que irão determinar o seu agir, que pode ser inicialmente um autocuidado baseado na cultura familiar ou da comunidade, como o uso de chás, simpatias, ou mesmo o remédio que um conhecido já utilizou para algo semelhante. Entretanto, quando isso não basta para fazer cessar o que ocorre no corpo, ele transfere para a Medicina a responsabilidade de nomear e tratar aquilo que o aflige. $\mathrm{O}$ paciente atribui ao médico e às equipes de saúde o lugar daqueles que portam o saber sobre o corpo e sobre a doença e espera deles a cura. Ao médico cabe a interpretação daquilo de que o paciente se queixa, identificando sintomas, examinando seu corpo e solicitando exames laboratoriais e/ou de imagem, para finalmente informar ao paciente o nome de sua doença, suas possíveis causas e consequências, e prescrever uma conduta que leve à cura ou ao controle da doença, ou, dito de outra forma, que garanta a vida. Assim, quando o paciente procura o médico, ele está, a priori, atribuindo a esse médico, uma relação de saber e de poder sobre o seu corpo. Ao receber um diagnóstico, o paciente necessita de um período de elaboração. Terá que "olhar" para o seu corpo, tecer teorias paralelas àquela fornecida pelo saber médico e construir uma compreensão sobre a doença. Dessa forma, o paciente pode ressignificar de modo menos doloroso a experiência do estar doente e a relação que estabelece com o tratamento, com os profissionais de saúde, com os familiares e com as perspectivas do futuro.

Entretanto, diante de algumas doenças crônicas, não curáveis, passíveis apenas de controle como é a DRC, o processo de elaboração psíquica da vivência do adoecimento apresenta outros rumos. Uma primeira mudança refere-se ao médico e à equipe de saúde, que para o paciente deixam de ser portadores do poder e saber "absoluto" sobre o corpo e passam a transitar entre o conhecimento e a dúvida. Outra questão refere-se à característica da DRC, que se apresenta com ausência de dor e de sensações físicas significativas que apontem para uma "doença de verdade". É apenas na dor que temos conhecimento dos nossos órgãos, "sentir dor informaria ao ego sobre a existência de um corpo constituído de órgãos, tornando-lhe possível a representação interna do próprio corpo" (Fernandes, 2005, p 82). E a DRC é "indolor".

É a partir do início do tratamento dialítico que o paciente com DRC se depara com o seu adoecimento, que até agora se apresentava como "não existente". É quando passa a portar uma marca concreta e visível, que é a presença de uma via de acesso para a diálise (fístula ou cateter), que o paciente ressignifica seu estado de saúde e se nomeia doente. O tratamento dialítico possibilita a manutenção da vida, mas para que seja um tratamento efetivo é necessário que o paciente faça uma escolha entre seguir ou não as recomendações médicas, o que em última instância significa a escolha entre viver ou morrer. Essa escolha é um processo que exige do paciente que ele consiga criar estratégias, sejam elas reais ou fantasiosas, para diminuir o sofrimento físico e psíquico. Diversos autores (Fructuoso, Castro, Oliveira et al., 2011; Kusleikaite, Bumblyte, Kuzminskis et al., 2010; Levy, 2008) têm afirmado que, a despeito dos grandes avanços tecnológicos introduzidos no tratamento dialítico, este tratamento torna a qualidade de vida dos pacientes bastante comprometida tanto nos aspectos físicos quanto nos emocionais e na vitalidade. (Higa, Kost, Soares et al., 2008) Estudos têm mostrado que os pacientes com maior tempo de tratamento dialítico apresentam progressivo comprometimento das relações familiares e sociais, maiores taxas de depressão e diminuição das atividades cotidianas desenvolvidas pelo paciente, como trabalho e atividades domésticas (Brito, 2009; Chilcot, Wellsted, Farrington, 2008; Kimmel, Cohen, Peterson, 2008; Martins \& Cesarino, 2005). Estudos descritivos e quantitativos identificam a piora da qualidade de vida e a presença de sintomas psicopatológicos, e tentam associá-las com o nível de informação que o paciente possui sobre a doença e o tratamento. Entretanto, constata-se o pequeno número de trabalhos acerca de intervenções no campo psicológico e psicanalítico capazes de minimizar esses efeitos tidos como negativos (Kimmel, Cohen, Peterson, 2008; Varela, Valquez, Bolanos \& col, 2011).

No dia a dia de trabalho, as equipes de saúde reconhecem o sofrimento dos pacientes que estão sob seus cuidados em tratamento dialítico e atribuem sentido ao mesmo. As equipes de saúde também desejam tratar esse sofrimento ou pelo menos propiciar melhora. Assim, existe um estranhamento na equipe quando o paciente, no momento da entrada em tratamento dialítico, reage de forma agressiva ou de recusa, mesmo após anos de tratamento conservador. Este tipo de reação emocional é mais aceita pela equipe em pacientes cuja entrada em diálise se deu de maneira emergencial, pois não teria havido tempo para assimilar a piora da condição renal. Qual seria então o tempo necessário ao paciente para lidar com a dor de entrar 
em diálise? Existiriam garantias de preparação e adaptação à entrada em diálise? Muitas vezes há suposições da equipe de saúde, diante da não compreensão do paciente, de que avaliações psicológicas poderiam identificar problemas cognitivos e/ou sintomas psicopatológicos que justificariam as dificuldades em compreender o diagnóstico e o prognóstico. A solução encontrada pela equipe de saúde é então solicitar uma interconsulta com um profissional da Psicologia.

Mirachi (2009) ao analisar os diversos contextos em que o profissional da Psicologia é solicitado dentro de um hospital geral evidencia a não adesão ao tratamento como uma das principais razões. Como exemplo, o autor apresenta o caso de um paciente que recusava o tratamento dialítico preferindo a morte, sem considerar o investimento da equipe em lhe passar conhecimentos acerca da doença e do tratamento para convencê-lo a se submeter à hemodiálise e, portanto, viver. A recusa do paciente subverte a lógica da busca por tratamento, e pode tocar em questões pessoais dos membros da equipe, como o modo de lidar com vida e morte. $\mathrm{O}$ atendimento psicanalítico desse paciente abriu a possibilidade de que ele falasse de aspectos conscientes e inconscientes relativos ao adoecimento, e assim se implicasse no tratamento. Casos como esse causam intensa comoção nas equipes de saúde, uma vez que a resposta subjetiva e emocional de muitos pacientes foge ao padrão imaginado e esperado pela equipe, pois mesmo com o fornecimento de toda a informação pertinente, essa pode ser apreendida ou não pelo paciente e, ainda que apreendida, pode haver sofrimento com a percepção da necessidade de se submeter a um tratamento dialítico. Cada paciente lida de forma única e, por vezes imprevista, com essa notícia.

Observa-se que a equipe de saúde insiste em enfatizar que ao paciente foi dada toda a informação sobre o seu adoecimento e sobre o tratamento proposto, e mesmo assim ele demonstra não ter assimilado as informações, não apresentando, contudo, nenhum déficit cognitivo que explique este fato. Nessas falas se percebe o desencontro entre o que um indivíduo diz ao outro e o que o outro entende. Ou seja, mesmo utilizando uma linguagem que lhes é comum, cada um atribui sentidos singulares ao que ouve. É na relação que cada um estabelece entre o que lhe foi dito e o que realmente escutou que fica denotada a dubiedade inerente à linguagem humana. Observa-se que o aumento de conhecimento e de informação para o paciente com DRC provoca alterações positivas no tratamento como um aumento na crença sobre a eficácia do tratamento e, consequentemente, uma maior e melhor adesão
(Karamanidou, Weiman, Horner, 2008). Entretanto a simples ampliação de conhecimento não dá sustentação nem conforta o sofrimento psíquico apresentado por esses pacientes. Embora a importância do sofrimento psíquico possa ser inferida da alta prevalência de depressão nesses pacientes, estudos de intervenções psicoterápicas para minimizar esse sofrimento não têm sido realizados (Nifa, Rudnick, 2010; Zimmermann, Carvalho \& col, 2004).

\section{Uma proposta de intervenção}

Diante do panorama apresentado, constata-se que o tratamento do paciente com DRC impõe relações complexas entre ele e a equipe de saúde, entre ele e sua doença e tratamento, e entre a equipe de saúde e a doença. Essas relações vão se modificando ao longo da evolução da perda renal e dos tratamentos prescritos. Para alguns pacientes tais relacionamentos se estabelecem de forma menos conflituosa, e o processo de adoecimento e o tratamento são vivenciados de forma menos angustiante, com o paciente elaborando suas perdas e readaptando sua vida à nova condição (Fayer, Nascimento, Abdulkader, 2008). Entretanto, outros pacientes vivenciam o adoecimento e o tratamento como algo extremamente limitante, estabelecendo uma relação conflituosa com a doença e com a equipe de saúde, não conseguindo aderir adequadamente à terapêutica proposta, o que contribui para o agravamento do quadro de saúde e aumenta o risco de morte (Fayer, 2010). Assim, não basta apenas analisar o prolongamento da vida como "estimativa de eficiência e eficácia (dos inegáveis avanços tecnológicos e terapêuticos na área da Nefrologia), mas principalmente a percepção subjetiva, e a capacidade funcional do paciente devem ser consideradas entre os resultados obtidos” (Romano, 1993, p. 7). É preciso que se reflita sobre o impacto que esse prolongamento da vida pode trazer na qualidade desta vida estendida (Velloso, 2001).

A eficácia dos cuidados aos pacientes com DRC, seja durante o tratamento conservador ou em programa de diálise, está diretamente associada à compreensão da complexidade dos fatores envolvidos na relação que o doente estabelece com sua doença e tratamento e que resultam na adesão ou na não adesão ao mesmo. Assim "a construção de estratégias de intervenção continua sendo um desafio para as equipes que atuam em nefrologia" e deve seguir "na direção de integrar seu trabalho, a partir do reconhecimento do paciente como um ser bio-psíquico-social" (Fayer, Nascimento, Abdulkader, 2008, p. 11). Estas ideias 
estão em consonância com a compreensão ampliada do conceito de saúde como como um estado de bem-estar físico, mental e social e não somente a ausência de doença ou enfermidade (World Health Organization, 1958). Até há pouco tempo, a atenção à saúde da população brasileira apresentava um caráter curativo e imediatista focado na figura do médico tendo as equipes de saúde um funcionamento multidisciplinar (Severo, Seminotti, 2010). Ou seja, diante da necessidade de um paciente ter o acompanhamento de diferentes profissionais de saúde, o tratamento era (ou ainda é) decomposto em unidisciplinaridades, onde cada profissional, separadamente, apresenta soluções parciais para o problema do paciente, mantendo com isso uma visão dissociada do paciente como um todo. Como nos coloca Jupiassu (1976, p. 72-73), fica-se diante de: "uma simples justaposição, num trabalho determinado, dos recursos de várias disciplinas, sem implicar necessariamente um trabalho de equipe e coordenado." Assim a multidisciplinaridade pode ser compreendida como algo restrito à reunião de várias disciplinas ou áreas do conhecimento, que permite uma justaposição de visões, mas não propicia a integração das mesmas, embora se deva reconhecer que tal modelo de funcionamento tem como objetivo somar esforços em benefício do paciente (Oliveira, 2009).

A implantação do Sistema Único de Saúde (SUS) trouxe o reconhecimento da saúde como um direito da população e um dever do Estado, redirecionando as políticas públicas de saúde a partir de "princípios doutrinários e organizativos de universalidade, eqüidade, integralidade, regionalização, hierarquização, descentralização administrativa e participação popular multidisciplinar" (Santos, Cutolo, 2003, p. 2). No entanto, é necessário repensar os modelos de atenção à saúde utilizados até agora, buscando-se novas formas de atuação em equipe de saúde que proporcionem maior eficácia interventiva no que concerne à integração dos aspectos bio-psíquico-social e cultural dos pacientes. Podemos compreender que a interdisciplinaridade surge do reconhecimento da complexidade dos fenômenos que envolvem o processo de adoecimento e seu tratamento, e da necessidade "de olhares diferenciados para um mesmo objeto e, assim, não pode prescindir da especialização" (Vasconcelos, 1997, p. 144). Assim, a interdisciplinaridade pode ser entendida como uma estratégia de ampliação e flexibilidade do conhecimento (On, 1995). Para Fazenda (2002, p. 31), a interdisciplinaridade é uma relação de "reciprocidade, de mutualidade" uma "co-propriedade", pois possibilita o diálogo e o estabelecimento de uma intersubjetividade, o que vem substituir a concepção do ser humano de fragmentária em unitária. Entretanto, o trabalho interdisciplinar requer das instituições de saúde e de seus profissionais flexibilidade e abertura para que ocorra o compartilhamento das análises e o reconhecimento dos limites de cada campo de conhecimento. Assim para que exista um "processo coletivo de conhecimento e de soluções no trabalho interdisciplinar há que estabelecer entre os profissionais um espaço e tempo diário para a definição de metodologias, técnicas e abordagens" (Santos, 2005, p. 30).

Tal ideal de trabalho, no dia-a-dia de uma equipe de Nefrologia torna-se bastante difícil, pois embora as características do tratamento dialítico exijam a presença de diferentes profissionais de saúde, como médico, enfermeiro, assistente social, nutricionista e psicólogo, a realidade concreta das instituições de saúde dificulta ou impede a integração contínua e adequada da equipe porque a rotina das atividades dos profissionais é tomada pelas necessidades específicas de suas especialidades. Entretanto, os cuidados demandados pelo paciente com DRC impõem aos membros da equipe a reflexão e o reconhecimento da necessidade de uma maior integração dos saberes com o objetivo de estabelecer intervenções que propiciem maior adesão ao tratamento, melhor qualidade de vida e, consequentemente, diminuição do sofrimento físico e psíquico dos pacientes. Nesse sentido, observa-se o surgimento de diferentes trabalhos em equipes de Nefrologia que se aproximam ou se sustentam numa prática interdisciplinar, como as discussões multiprofissionais dos casos, os grupos psicoeducativos e os grupos de sala de espera (Cezaretto, 2010; Dias, Silveira, Witt, 2009; Fayer, 2010; Silva, Feldmam, Lima et. al., 2006; Teixeira \& Zanetti, 2006). A busca por uma melhor qualidade nas intervenções, e por um melhor modelo de funcionamento, é uma preocupação da nossa equipe de saúde. Nela é rotina a discussão dos casos e o encaminhamento de qualquer profissional da equipe para outro quando isto se faz necessário. Essa prática não foi previamente planejada e nem teorizada. Entretanto, ela se consolidou como promotora de efeitos terapêuticos observáveis, na medida em que o paciente relata benefício em suas consultas. A troca subsequente entre os profissionais acerca daquele caso produz conhecimento que se incorpora à prática profissional. A equipe de saúde passa a compreender e melhor ajudar seus pacientes a partir do momento em que cada profissional, falando sobre os pacientes, tem a oportunidade de compartilhar a fala e a escuta dos 
outros membros da equipe que partindo de outros campos de conhecimento refletem sobre sua própria prática (Bekéi, Caffaratti, Freue et al., 1982).

A partir da avaliação dos pedidos de acompanhamento psicológico para pacientes internados, constatou-se que as razões que justificavam os diferentes pedidos revelaram-se bastante semelhantes: dificuldades em compreender o motivo da internação prolongada e das orientações médicas, quadros de ansiedade associados à internação ou a procedimentos diagnósticos, sofrimento psíquico da entrada em tratamento diálise, etc. Semelhanças também se observaram nas falas dos pacientes durante o atendimento psicológico individual e nos diálogos travados com a equipe após esse atendimento. A reflexão da equipe sobre estes dados levou à construção do grupo de atendimento interdisciplinar aberto e rotativo como uma nova intervenção junto aos pacientes internados na nossa enfermaria de Nefrologia. O grupo foi concebido como um espaço de expressão e acolhimento das diversas demandas dos pacientes, um instrumento facilitador da sua escuta. Na medida em que os pacientes falavam de si e ouviam a fala de outros em situação semelhante, criava-se a possibilidade de identificações, de desconstrução de fantasias e da construção de conhecimento sobre a doença e o tratamento. Assim essa intervenção proposta abre para o paciente internado "Um espaço para que fale e possa ser escutado de um outro lugar onde ele não é só aquele paciente, doente ou o número de um leito" (Moura, 1999, p. 14).

\section{Algumas reflexões teóricas sobre $o$ atendimento em grupo}

Tomando a psicanálise como norteadora para a compreensão do trabalho grupal interdisciplinar desenvolvido com os pacientes numa enfermaria de nefrologia, alguns aspectos teóricos devem ser considerados.

Como apontado por Kaës (1997), é um fato fundamental e irredutível, a dupla contingência sob a qual todo ser humano nasce: a condição biológica de fragilidade de seu corpo e a natureza social, constituída das intersubjetividades do grupo humano. Nascemos a partir da determinação de outro humano, de seu ato e desejo. Como recém-nascido, o ser humano depende fisicamente de outro, normalmente a mãe, que o alimente que dele cuide, que atribua sentidos e responda afetivamente as suas expressões e movimentos do seu corpo, propiciando o estabelecimento da primeira relação objetal. É no desdobramento desta primeira relação humana que o indivíduo se constitui e estabelece todas as demais relações sociais (Spitz, 1987).

A inserção do indivíduo em grupos se inicia no seu nascimento (família) e se mantém por toda a vida (família, escola, trabalho, amigos). O indivíduo está sempre em relação com um outro. Ao nascermos, já pertencemos a um grupo, que por sua vez está dentro de outros grupos, numa cadeia interrelacionada. Como nos diz Kaës (1997, p. 106), nascemos:

[...] elos no mundo, herdeiros, servidores e beneficiários de uma cadeia de subjetividades que nos precedem e de que nos tornamos contemporâneos: seus discursos, sonhos, seus recalcados que herdamos, a que servimos e de que nos servimos, fazem de cada um de nós os sujeitos do inconsciente submetidos a esses conjuntos, partes constituídas e constituintes desses conjuntos.

A vida grupal produz alterações em nossa vida psíquica. (Guimarães, Celes, Canezin, 2007). O grupo exerce funções fundamentais na estruturação psíquica e na posição subjetiva de todas as pessoas (Kaës, 1997). Neste sentido, o atendimento em grupo como forma de intervenção em saúde, mostra-se como uma estratégia importante, na medida em que parte do pressuposto da essência social do homem, na qual ele sempre estará em relação com um outro semelhante, construindo e reconstruindo a própria realidade. Assim a intervenção em grupo apresenta uma dupla função: a de investigação e a de tratamento das formações e dos processos da realidade psíquica presentes num grupo (Kaës, 1997).

A estrutura e dinâmica do trabalho em grupo, bem como sua eficácia são bem conhecidas no meio da saúde, através dos estudos de Bion (1975), Anzieu (1993), Baremblitt (1986), Bleger (1980) e Costa (1989) que demonstraram o benefício terapêutico da própria condição de "falar em grupo". O grupo nunca é a somatória de seus membros, mas é o resultado da interação entre indivíduos (Kaës, 1997; Lewin, 1989; Moreno, 1970). Ou mais que isto o indivíduo é o grupo (Kaës, 1997). Pode ser conceituado, também, como um conjunto de pessoas que reconhecem a própria singularidade e interagem compartilhando normas na realização de objetivos comuns (Bleger, 1980; Osório, 2003). O processo grupal é um processo dialético no qual o indivíduo e o grupo são as faces da mesma moeda. A estrutura e dinâmica grupal podem propiciar a seus integrantes recursos para substituir algo que falte a cada indivíduo. A partir das associações produ- 
zidas livremente no grupo, os indivíduos podem tomar para si o que lhe falta e significar suas vivencias emocionais (Kaes, 1997).

$\mathrm{Na}$ enfermaria de Nefrologia, o paciente encontra-se, muitas vezes, frente ao inesperado, sem respostas às perguntas que são conseqüência de sua condição de internação: "por que comigo?", "por que agora?", "por que a doença?". A internação é um fato comum a todos o que possibilita uma identificação inicial entre os pacientes, o que é indispensável para o surgimento de questões, que colocadas por alguns, afeta a cada indivíduo (Bion, 1975). O grupo, por suas características, estimula a integração social, a percepção sobre si a partir do olhar e da fala do outro, e a comunicação, que deve ser entendida como um processo consciente ou não, verbal ou não, seja de cada um dos participantes ou do grupo como um todo (Foulkes, 1970). O partilhar no grupo propicia o fortalecimento do vínculo, permitindo que os indivíduos compartilhem palavras e códigos, saberes e competências, atribuindo sentidos a objetos do mundo e, portanto inserindo-os no universo sociocultural (Carvalho, Bastos, Rabinovich et al., 2006). No processo grupal, como nos enfatiza Pichon-Rivière (1995), a comunicação é considerada um fator essencial, primitivo e imperioso para o ser humano. Este processo de comunicação que ocorre entre os pacientes, pacientes e equipe e entre os membros da equipe, permanece e se reproduz para fora do espaço grupal. Anzieu (1993), por exemplo, refere que a oportunidade de participar de um grupo permite a seus membros efetuarem trocas que não cessam após o término do grupo. A possibilidade da escuta interdisciplinar permite ao paciente um reposicionamento diante das imagens que possuía sobre as relações institucionais. Se antes as questões decorrentes de seu quadro de saúde deviam receber atenção compartimentada, ou seja, "ao médico às questões de seu corpo, ao psicólogo às questões de sua psique, etc.", no grupo, ele é convidado a dizer de si, e os profissionais, na mesma medida, a se despirem de suas especialidades para ouvi-los, primeiramente, como subjetividades, para depois, acolher suas demandas e a elas responder. O espaço grupal se dá a partir da livre associação dos pacientes, da leitura da equipe de suas demandas e consequentemente respostas, sejam elas de acolhimento do sofrimento, de informação objetiva acerca de uma dúvida, de apontamento às questões que circulam no espaço grupal, ou mesmo, de interpretação do discurso e dinâmica grupal. Assim, a intervenção proposta não é apenas um grupo de orienta- ção às questões relativas ao adoecimento e tratamento é bem mais do que isto.

\section{Um exemplo de grupo rotativo interdisciplinar}

Os atendimentos em grupo interdisciplinar tinham as seguintes características: 1. Local: enfermaria da Nefrologia; 2. Frequência: semanal, com 1 hora de duração; 3. Participação: aberta a todos os pacientes internados e assuntos propostos por eles; 4. Equipe de saúde: uma médica, um enfermeiro, uma assistente social, uma nutricionista e duas psicólogas. Cada profissional intervinha na medida em que se sentia convocado a responder mesmo não sendo relativo à sua especialidade, mas relativo à sua leitura da demanda do paciente. Como exemplo, apresentamos um recorte de um dos grupos realizados.

O grupo foi iniciado pela psicóloga: "Este grupo é para que vocês possam falar da internação e de suas dúvidas..." e pede que cada um se apresente. Os pacientes e os membros da equipe de saúde vão então se apresentando, mas, a despeito da recomendação inicial dada pela psicóloga, os pacientes vão fazendo questionamentos.

COMENTÁRIO: Percebe-se que para muitos pacientes há uma urgência em dizer sobre sua condição de saúde e assim sendo a informação inicial de que tratava de um grupo para trazerem suas questões se sobrepõe à informação de que primeiramente precisam se apresentar. Assim, os integrantes do grupo se apropriam do espaço ofertado e constroem a dinâmica do grupo ao solicitar informações ou relatarem seus pensamentos e fantasias.

Após se apresentar a médica diz: "o Sr. JO perguntou se o rim dele (que) está funcionando $50 \%$, pode piorar ou não." O paciente JO corrige: "E pode melhorar?" A médica: "(Pode) melhorar ou não. Quem tem doença no rim a tendência é o rim piorar aos poucos... Pode curar ou não. [...] $O$ objetivo da gente é sempre tentar melhorar. Se chegamos à conclusão que não dá para melhorar, a gente consegue que piore bem devagar." O paciente JO então pergunta sobre diálise.

COMENTÁRIO: Observa-se que o acolhimento dado pela médica à questão do $\mathrm{Sr}$. JO propiciou que ele se aproximasse de seu medo "de piora e de perda renal" e que perguntasse sobre a diálise, desconstruindo as suas fantasias.

A médica, desenhando na lousa: "O rim pega o sangue da gente, filtra e coloca na urina o que não precisa, e deixa no corpo da gente o que a gente pre- 
cisa e [o rim] regula isso muito bem. Quando o rim para de funcionar, essa função (filtração) fica ruim e $o$ sangue fica acumulando o que não devia. Como a gente faz se o rim não filtra? Precisamos limpar o sangue. A máquina não faz tudo que o rim faz, mas limpa o sangue. [E o sangue mais limpo] volta para a pessoa pelo cateter. Outro jeito [do sangue entrar e sair da máquina] é pegar uma veia aqui e uma artéria [apontando na própria mão] e fazer uma fístula. Vamos desenhar a mão da JQ." A paciente JQ: "Faz uma mão bem gorda." Através de desenhos a médica explica como é uma fístula e como se faz uma diálise peritoneal. A paciente G: "E limpar o sangue nunca é com remédio?" A médica: "Com remédio, não".

COMENTÁRIO: As falas de JQ e G demonstram como a relação inicial estabelecida entre JO e a médica com o acolhimento de suas dúvidas e do medo, permitiu que outros pacientes expressassem seus pensamentos e fantasias. Um fator importante no desenvolvimento deste tipo de grupo é a construção de uma linguagem possível entre paciente e equipe de saúde o se observa na busca da médica por recursos metonímicos e metafóricos para a interlocução com os pacientes, o que é prontamente respondido pelos mesmos por meio dos diálogos entre eles e por novos comentários.

Respondendo à solicitação da paciente $\mathrm{C}$ a médica explica o que é lúpus. Paciente JQ: "E por que [no lúpus, os anticorpos] acham logo o rim?" A médica: "Cada pessoa que tem lupus tem um jeito de manifestação." Paciente JQ: "Eu já tive vários." A médica pergunta para a paciente JQ: "E por que você está aqui (internada)?" Paciente JQ: "Porque [o lúpus] atacou o rim." A paciente G: "Todo o problema de rim é obrigado a fazer hemodiálise?" A médica: "Não". A paciente G: "[Para saber se não precisa mais fazer hemodiálise] é só se parar? E como sabemos?" A médica explica que o funcionamento dos rins é avaliado por um exame de sangue chamado creatinina e que para saber se o rim vai voltar a funcionar, muitas vezes, é preciso tirar um pedacinho do rim e olhar para ver se só tem cicatriz. Quando só tem cicatriz o rim não volta a funcionar. A paciente G: "Estou com muito medo de tirar esse pedacinho."A psicóloga pergunta a G: "Você está com medo da biópsia?" e depois, dirigindo-se aos demais: "Alguém já fez?" Os pacientes $\mathrm{C}$ e $\mathrm{A}$ respondem que já fizeram biópsia. Paciente C: "Não dói. É anestesiado. Não dói." Paciente G: "Eu morro de medo. Dá ponto?" Paciente C: "Não." Paciente JQ: "É tipo vão dar uma agulhada e uma pinçada." O paciente JO: "Tem dois tipos de fazer [biópsia]." A psicóloga: "Tem dois tipos: a [biópsia] a céu aberto e essa que vocês fizeram." pedindo confirmação da médica. A médica passa a explicar o que é a biópsia de rim: "Primeira coisa, onde está seu rim?" [perguntando para a paciente G] Como não obtém resposta, tira o avental e apontando para as próprias costas, indica onde estão os rins. Neste momento o paciente A passa mal. É socorrido e levado para sua cama. O grupo é retomado após 15 minutos. A médica: "Às vezes, quando a gente toca em algo que a gente tem muito medo - não estou dizendo que é o caso do Sr. A - o nosso coração bate devagarzinho. É uma maneira que a gente tem de escapar do medo. $O$ que o $\mathrm{Sr}$. A teve nós não sabemos mas vamos investigar." Paciente G: "Eu tenho muito medo." Paciente JQ: "Ah! Não tem que ter medo." Paciente G: "Se eu vejo uma barata, eu morro de medo." Paciente PB: "Eu tenho medo de barata, mas eu mato, uso inseticida, com veneno." A psicóloga: "A paciente MA tem medo do cateterismo, ela [paciente G] da biópsia. $O$ que a gente coloca no medo é algo que achamos que não vamos suportar." e depois pergunta para a paciente MA: "O que a Sra. imagina do cateterismo?" Paciente MA: "Que vou morrer." Paciente JQ: "Ah! Um dia vai mesmo." A psicóloga pergunta para a paciente G: "E você o que imagina da biópsia?" Paciente G: "Eu imaginava que ia abrir um buraco e tirar um pedaço..., ver tudo podre e morrer." A psicóloga: "É por isso que fazemos esse grupo para entender o que acontece."

COMENTÁRIO: A sequência de diálogos acima ilustra como o trabalho em equipe interdisciplinar permite que o paciente tenha acesso às suas angústias e que fale sobre elas construindo assim formas de enfrentamento e diminuindo o sofrimento psíquico. Embora o grupo contasse com a presença da psicóloga, o trabalho interdisciplinar permitiu à médica o apontamento da angústia que muitas vezes os pacientes vivenciam. Com isso abriu-se espaço para que outros pacientes falassem sobre o tema permitindo outros apontamentos sobre as suas identificações e angústias, o que possibilitou o reconhecimento e elaboração das mesmas. Observa-se nos trabalhos em grupo que para o paciente falar sobre assuntos tão difíceis como medos e sofrimento físico, muitas vezes é necessária a diminuição da tensão e da angústia, através do uso de brincadeiras, como vimos no trecho acima. Se antes falavam do medo da morte e fantasias associadas a isso, precisou-se romper a angústia introduzindo piadas na questão seguinte trazida pela paciente JQ. 
A psicóloga pergunta para a paciente MA: "A Sra. sabe o que é o cateterismo?". "Não" a paciente responde.

COMENTÁRIO: Através da fala coletiva do grupo sobre os medos de cada um, que é um processo identificatório, a psicóloga retorna aos medos da paciente MA a fim de ajudá-la a enfrentar seu tratamento.

A médica, novamente com o uso de desenhos, explica como é feito o cateterismo cardíaco e o que é um enfarto. A paciente MA: "Este é o meu medo." A médica: "Você precisa falar com o seu médico." E explica que o medo provoca algumas reações no corpo podendo alterar os batimentos cardíacos. Paciente JQ: "Então aquele paciente até desmaiou." A psicóloga: "Não se sabe se foi por isso. Então quando se fizer um exame precisa estar com o medo controlado para não sofrer."

COMENTÁRIO: Observa-se na fala de JQ a presença de uma teoria sobre o que aconteceu com o outro paciente do grupo. Foi necessário para ele criar uma explicação para o ocorrido, para diminuir o medo de que acontecesse algo semelhante a ele próprio, sendo este um mecanismo de defesa frente ao inesperado. A fala sequencial da psicóloga, instaurando uma dúvida, buscou desconstruir a fantasia expressa no grupo por JQ.

Paciente MA: "Tenho medo de várias coisas." A psicóloga: "A Sra. tem muitos medos?" Paciente MA: "Tenho." A psicóloga: "A Sra. nunca tratou?" Paciente MA: "Não." A psicóloga explica que "o medo se trata." e pergunta às pacientes MA e G se já fazem algum acompanhamento com a Psicologia. Como elas não fazem, diz que vai "pedir para alguém conversar com vocês ou eu mesma venho conversar." Paciente MA: "Mas tem jeito?"A médica e a psicóloga respondem que sim.

COMENTÁRIO: O grupo interdisciplinar também é um espaço de triagem de demandas e de se fazer encaminhamentos, sejam eles para uma melhor orientação do profissional que acompanha o caso, ou para outro tratamento que se revelou necessário.

\section{COMENTÁRIOS FINAIS}

$\mathrm{Na}$ dinâmica descrita acima podemos identificar diferentes aspectos da intervenção proposta: o seu caráter interdisciplinar, com os membros da equipe de saúde participando e incentivando a participação dos pacientes; o fato do grupo ser aberto e rotativo com alguns pacientes já tendo participado de outros grupos, os pacientes irem chegando e saindo à medida do que estava acontecendo na enfermaria; o seu caráter informativo com inúmeros assuntos discutidos (lúpus, diálise, biópsia renal, cateterismo, etc) e traduzidos da linguagem médica para uma linguagem leiga (buraco, peneirinha); o seu caráter grupal onde um paciente se apropria da fala do outro e faz perguntas com o intuito de alcançar um saber mais amplo do que tão somente buscar saber sobre a própria doença, etc. $\mathrm{O}$ grupo interdisciplinar permitiu aos pacientes expressarem livremente as suas dúvidas e fantasias, propiciando assim que não apenas os membros da equipe interviessem sobre aquilo que foi dito, mas também que os demais pacientes desconstruíssem as próprias fantasias e assimilassem informações significativas acerca da doença e tratamento, possibilitando com isto um maior comprometimento no autocuidado e na adesão (Santos, Frota, Cruz et al., 2005). É importante ressaltar que o modelo proposto pressupõe o comprometimento de toda a equipe de saúde com a interdisciplinaridade.

\section{REFERÊNCIAS}

Anzieu, D. (1993). O grupo e o inconsciente. O imaginário grupal. São Paulo: Casa do Psicólogo.

Baremblitt, G. (1986). Grupos: teoria e técnica. (2 ${ }^{\mathrm{a}}$ ed.) Rio de Janeiro: Graal.

Bekéi, M., Caffaratti, N., Freue, J.M. et al. (1982). Grupos interdisciplinarios. In I. Luchina \& M. Bekéi (Orgs.), El grupo Balint: Hacia um modelo clínico-situacional. Buenos Aires/ Barcelona: Paidos.

Bion, W. R. (1975). Experiência com grupos: fundamentos da psicoterapia de grupos. Rio de Janeiro: Imago.

Bleger, J. (1980). Temas de Psicologia: entrevistas e grupos. São Paulo: Martins Fontes.

Brito, D. C. S. (2009). Cuidando de quem cuida: estudo de caso sobre o cuidador principal de um portador de insuficiência renal crônica. Psicol Estud 14, 603-607.

Carvalho, A. M., Bastos, A. C. S. B., Rabinovich, E. P. et al. (2006). Vínculos e rede sociais em contextos familiares e institucionais: uma reflexão conceitual. Psicol Estud 11, 589-598.

Cezaretto, A. (2010). Intervenção Interdisciplinar para a prevenção de diabetes mellitus sob a perspectiva da psicologia. Benefícios na qualidade de vida. Dissertação de Mestrado. Universidade de São Paulo, São Paulo.

Chilcot, J., Wellsted, D., Farrington, K. (2008). Screening for depression while patients dialyse: an evaluation. Nephrol Dial Transplant 23, 2.653-2.659. 
Costa, J. F. (1989). Psicanálise e contexto social: imaginário psicanalista, grupos e psicoterapias. Rio de Janeiro: Campus.

Dias, V. P., Silveira, D. T., Witt, R. R. (2009). Educação em saúde: $\mathrm{O}$ trabalho de grupos em atenção primária. Rev APS 12, 221-227.

Fayer, A. A. M., Nascimento, R. A., Abdulkader, R. C. R. M. (2008). Humanização do atendimento em Nefrologia. In J. Cruz J., H. M. Mazzarolo-Cruz, G. M. Kirstajn \& R. T. Barros (Orgs.), Atualidades em Nefrologia-10. (pp. 10-15) São Paulo: Sarvier Editora de Livros Médicos.

Fayer, A. A. M. (2010). Repercussões psicológicas da doença renal crônica: comparação entre pacientes que iniciam o tratamento hemodialítico após ou sem seguimento nefrológico prévio. Dissertação de mestrado, Universidade de São Paulo, São Paulo.

Fazenda, I. C. A. (2002). Interdisciplinar: um projeto em parceria. (5 $5^{\mathrm{a}}$ ed) São Paulo: Loyola.

Fernandes, M. H. (2005). Corpo. ( $2^{\mathrm{a}}$ ed). São Paulo: Casa do Psicólogo.

Foulkes, S. H. (1970). Psichothérapie et analyse de groupe. Paris: Payot.

Fructuoso, M. R., Castro, R., Oliveira, I. et al. (2011). Quality of life in chronic kidney disease. Nefrologia 31, 91-96.

Guimarães, V. G., Celes, L. A. M., Canezin, V. (2007). O psíquico e o social numa perspectiva metapsicológica: o conceito de identificação em Freud. Psic Teor Pesq 23, 341-346.

Higa, K., Kost, M. T., Soares, D. M. et. al. (2008). Quality of life of patients with chronic renal insufficiency undergoing dialysis treatment. Acta Paul Enferm 21, 203-206.

Jupiassu, H. (1976). Interdisciplinaridade e patologia do saber. Rio de Janeiro: Imago.

Kaës R. (1997). O grupo e o sujeito do grupo: elementos para uma teoria psicanalítica do grupo. São Paulo: Casa do Psicólogo.

Karamanidou, C., Weinman, J., Horner, R. (2008). Improving haemodialysis patients' understanding of phosphate-binding medication: a pilot study of a psycho-educational intervention designed to chance patients' perceptions of the problem and treatment. Br J Health Psychol 13, 205-214.

Kimmel, P. L., Cohen, S. D., Peterson, R. A. (2008). Depression in patients with chronic renal disease: Where are we going? $J$ Renal Nutr 18, 99-103.

Kusleikaite, N., Bumblyte, I. A., Kuzminskis, V. et al. (2010). The association between health-related quality of life and mortality among hemodialysis patients. Medicina (Kaunas) 46, 531-537.

Levy, N. B. (2008). What is psychonephrology? J Nephrol 21 (suppl 13), S51-S53.

Lewin, K. (1989). Problemas de dinâmica de grupo. São Paulo: Cultrix.

Martins, M. R. I., Cesarino, C. B. (2005). Qualidade de vida de pessoas com doença renal crônica em tratamento hemodialítico. Rev Latino-Am Enfermagem 13, 670-676.
Mirachi, C. B. (2009). A questão dos discursos na instituição hospitalar a partir da psicanálise lacaniana. Dissertação de mestrado. Pontifícia Universidade Católica de Minas Gerais, Belo Horizonte.

Moreno, J. L. (1970). Fondements de la sociométrie. (2 ${ }^{\mathrm{eme}}$ ed.) Paris: Presses Universitaires de France.

Moura, M. D. (1998). Psicanálise e Hospital. Rio de Janeiro: Revinter.

Nifa, S., Rudnick, T. (2010). Depressão em pacientes renais crônicos em tratamento de hemodiálise. Rev SBPH 13, 64-75.

Oliveira, R. C. (2009). Equipe interdisciplinar em hospital geriátrico e gerontológico: (re)ligando ofícios. Dissertação de Mestrado, Pontifícia Universidade Católica de São Paulo, São Paulo.

On, M. L. R. (1995). O serviço social e a perspectiva interdisciplinar. In M. L. Martinelli, M. L. R. On \& S. T. Muchail (Orgs.), $O$ uno e o múltiplo nas relações entre as áreas do saber. São Paulo: Cortez.

Osório, L. C. (2003). Psicologia grupal: uma nova disciplina para o advento de uma era. Porto Alegre: Artmed.

Pichon-Rivière, E. (1995). Teoria do vínculo. (5 $\mathrm{a}$ ed.) São Paulo: Martins Fontes.

Romano, B. W. (1993). Qualidade de vida: teoria e prática. Rev SoCESP 3, 6-9.

Santos, M. A. M., Cutolo, L. R. A. (2003) A interdisciplinaridade e o trabalho em equipe no programa de saúde da família. Arq Catarin Med 32, 65-74.

Santos, Z. M. S., Frota, M. A., Cruz, D. M. et al. (2005). Adesão do cliente hipertenso ao tratamento: análise com abordagem interdisciplinar. Texto Contexto Enferm 14, 332-340.

Santos, N. M. C. (2005). Interdisciplinaridade: entre o desejo e a prática dos profissionais do transplante cardíaco no Instituto Dante Pazzanese de Cardiologia. Programa de Estudos PósGraduados em Serviço Social. São Paulo: Pontifícia Universidade Católica.

Severo, S. B., \& Seminotti, N. (2010). Integralidade e transdisciplinaridade em equipes multiprofissionais na saúde coletiva. Ciênc Saúde Coletiva 15, 1.685-1.698.

Silva, T. R., Feldmam, C., Lima, M. H. A. et al.. (2006). Controle de diabetes Mellitus e hipertensão arterial com grupos de intervenção educacional e terapêutica em seguimento ambulatorial de uma unidade básica de saúde. Saúde Soc 15, 180-189.

Spitz, R. A. (2004). O primeiro ano de vida. ( $3^{\mathrm{a}}$ ed.) São Paulo: Martins Fontes.

Teixeira, C. R. S., Zanetti, M. L. (2006). O trabalho multiprofissional com grupo de diabéticos. Rev Bras Enferm 59, 812-817.

Varela, L., Valquez, M. I., Bolanos, L. et al. (2011). Predictores psicológicos de la calidad de vida relacionada com la salud en pacientes en tratamiento de diálisis peritoneal. Nefrologia 31, 97-106.

Vasconcelos, E. M. (1997). Serviço social e interdisciplinaridade. Serv Soc Soc 54, 132-157. 
Velloso, R. L. M. (2001). Efeitos da hemodiálise no campo subjetivo dos pacientes renais crônicos. Cogito 3, 73-82.

World Health Organization (1958). Constitution of the World Health Organization. Annex I. In Ten years of World Health Organization. Geneve: WHO.

Zimmermann, P. R., Carvalho, J. O. et al. (2004). Impacto da depressão e outros fatores psicossociais no prognóstico de pacientes renais crônicos. Rev Psiquiatr Rio Gd Sul 26, 312-318.

Recebido em: 15/05/2012

Revisado em: 04/01.2013

Primeira Decisão Editorial em: 12/03/2013

Aceito em: 20/03/2013 